University of Wollongong

Research Online

Faculty of Engineering - Papers (Archive)

Faculty of Engineering and Information

Sciences

$1-1-2011$

\title{
The effect of sulfur concentration in liquid iron on mineral layer formation during coke dissolution
}

\author{
Michael W. Chapman \\ mchapman@uow.edu.au \\ Brian J. Monaghan \\ University of Wollongong, monaghan@uow.edu.au \\ Sharon Nightingale \\ University of Wollongong, sharon@uow.edu.au \\ John G. Mathieson \\ BlueScope Steel, John.Mathieson@bluescopesteel.com \\ Robert J. Nightingale \\ University of Wollongong, robertn@uow.edu.au
}

Follow this and additional works at: https://ro.uow.edu.au/engpapers

Part of the Engineering Commons

https://ro.uow.edu.au/engpapers/1349

\section{Recommended Citation}

Chapman, Michael W.; Monaghan, Brian J.; Nightingale, Sharon; Mathieson, John G.; and Nightingale, Robert J.: The effect of sulfur concentration in liquid iron on mineral layer formation during coke dissolution 2011, 642-651.

https://ro.uow.edu.au/engpapers/1349

Research Online is the open access institutional repository for the University of Wollongong. For further information contact the UOW Library: research-pubs@uow.edu.au 


\title{
The Effect of Sulfur Concentration in Liquid Iron on Mineral Layer Formation During Coke Dissolution
}

\author{
MICHAEL W. CHAPMAN, BRIAN J. MONAGHAN, SHARON A. NIGHTINGALE, \\ JOHN G. MATHIESON, and ROBERT J. NIGHTINGALE
}

\begin{abstract}
The effects of sulfur concentration in liquid iron on mineral layer development between coke and iron as coke dissolves in a 2 mass pct carbon-iron liquid have been investigated at $1773 \mathrm{~K}$ $\left(1500{ }^{\circ} \mathrm{C}\right)$. The initial sulfur in iron concentrations used ranged from 0.006 to 0.049 mass pet. Key findings include that the two-stage dissolution behavior exhibited in the carbon transfer from coke to iron, as reported in a previous study by the authors, at low initial sulfur in iron contents, was also apparent at the higher values used in this study. This two-stage behavior was attributed to a change in the mineral layer density as a result of changes in mineral morphology at the interface. In addition to confirming the two-stage behavior of the carbon-transfer kinetics at the higher sulfur concentration in iron levels, after a period of time, a solid calcium sulfide layer formed on the mineral layer. The sulfide layer formed after approximately 40 minutes, and the proportion of sulfide in the mineral layer increased with increased experimental time and initial sulfur concentration in iron. It was usually found at the iron side of the mineral layer and was associated with calcium-enriched calcium aluminates. Thermodynamic analysis of this layer confirmed that the sulfide is stabilized as the mineral layer is enriched by calcium.
\end{abstract}

DOI: $10.1007 / \mathrm{s} 11663-011-9519-0$

(C) The Minerals, Metals \& Materials Society and ASM International 2011

\section{INTRODUCTION}

COKE is a key reagent in blast furnace iron production. It is the primary reductant of the ore, the fuel for the furnace smelting, used to control the gas permeability required for high blast furnace iron production rates, and the source of carbon in the liquid iron. ${ }^{[1]}$ This investigation is focused on the coke-iron reactions occurring in the blast furnace hearth below the slag layer where coke is immersed in liquid iron. Liquid iron entering this region contains more than 2 mass pct carbon and picks up its final carbon while percolating though the coke-packed bed in the deadman and hearth regions of the blast furnace. ${ }^{[1]}$

Metallurgical coke typically contains 8 to 12 mass pct of inorganic mineral matter. ${ }^{[2]}$ As coke dissolves into the liquid iron, the insoluble components of this inorganic mineral matter can potentially form a layer at the cokeiron interface, inhibiting carbon dissolution. ${ }^{[3-14]}$ Recent studies by the current author ${ }^{[4,5,7]}$ have demonstrated a link between coke dissolution kinetics and the morphology of the mineral layer formed at the interface. Phase

MICHAEL W. CHAPMAN, Ironmaking Production Engineer, formally with the PYROmetallurgical Research Group, University of Wollongong, Wollongong, NSW 2522, Australia, is now with BlueScope Steel Limited, Port Kembla, NSW 2505, Australia. BRIAN J. MONAGHAN and SHARON A. NIGHTINGALE, Associate Professors, are with the PYROmetallurgical Research Group, University of Wollongong. Contact e-mail: monaghan@uow.edu.au JOHN G. MATHIESON, Senior Research Manager, and ROBERT J. NIGHTINGALE, Senior Ironmaking Production Engineer, are with BlueScope Steel Limited.

Manuscript submitted July 13, 2010.

Article published online April 20, 2011. morphology is partly a function of composition and it is therefore expected that morphology effects of the mineral layer at the interface will be a function of the coke mineral composition. Details of sulfide formation in the mineral layer were not discussed in the previous articles but are elaborated on as the main subject of this study.

\section{A. Previous Work}

Few data exist on the form, composition, and morphology of the layer that forms during coke dissolution in liquid iron. Recent studies by the current authors ${ }^{[4,5,7]}$ have related measurements and observations of the composition and morphology of the mineral layer formed at the coke-liquid iron interface to the rate of coke dissolution. The mineral layer formed was primarily a calcium aluminate that progressively became enriched in calcium as the dissolution reaction proceeded. The calcium enrichment led to a change in morphology of the mineral layer that in turn slowed the rate of coke dissolution ${ }^{[4]}$ in a step change.

Information on what type of layer forms on the coke as the dissolution reaction proceeds comes from an excellent study by Gudenau et al. ${ }^{[8]}$ who present data on the ash (mineral matter) found on the surface of coke particles dipped in liquid iron and from sessile drop studies.

In other liquid iron sessile drop studies, performed by Sahajwalla et al. ${ }^{[9-11,14]}$ a drop of liquid iron was reacted with a carbonaceous substrate, and an ash (mineral) layer formed at the iron-carbonaceous material interface. General observations of the droplet 
surface in these studies indicated that the ash (mineral) layer at the interface was initially rich in $\mathrm{Al}_{2} \mathrm{O}_{3}$; however, as the reaction time increased, the proportion of $\mathrm{CaO}$ increased-in some cases, in excess of that expected from coke ash composition alone. ${ }^{[9]}$ Sulfur also was concentrated at the interface as a complex iron calcium sulfide.

In the coke dissolution literature, general agreement persists that sulfur has a retarding effect on the rate of carbon dissolution in liquid iron. However, the mechanism has not been conclusively determined. Possible mechanisms suggested in the literature fit into the following broad groups:

(a) Sulfur influences the physical properties of the liquid iron-specifically the kinematic viscosity, carbon diffusivity, and carbon saturation, the effect of which is manifested in a reduced carbon dissolution rate. ${ }^{[13,15,16]}$

(b) A reduction in the available surface area is caused by the adsorption of surface-active sulfur atoms at the reaction interface physically limiting the sites available for carbon dissolution. ${ }^{[17-22]}$

(c) Other interfacial effects as demonstrated by the presence of sulfur in the liquid iron decrease the wettability of the iron on the carbonaceous surface. $^{[23]}$

Determining how the sulfur affects coke dissolution in iron is beyond the scope of this study. The focus of this study was to characterize and explain the sulfur concentration in iron effects on mineral layer formation at the coke-iron interface.

\section{B. Experimental}

1. Experimental procedure

A series of coke (carbon) dissolution experiments were conducted in which $35 \mathrm{~g}$ of crushed coke $(-2 \mathrm{~mm}+0.5 \mathrm{~mm})$ was added directly to the top surface of $572 \mathrm{~g}$ of liquid iron 2 mass pet carbon alloy. The liquid iron was frequently sampled with a $1-\mathrm{mm}$ inner diameter quartz tube over a period of 3 hours. The experiment was carried out in a dry argon atmosphere with a flow rate of $0.72 \mathrm{~L} / \mathrm{min}$. These experiments were conducted at $1773 \mathrm{~K}\left(1500{ }^{\circ} \mathrm{C}\right)$ using iron with three different initial sulfur concentrations. The temperature and sulfur levels were chosen to replicate what might be expected in the lower zone deadman area of a blast furnace.

A complementary series of quenched coke (carbon) dissolution experiments was performed in which $10 \mathrm{~g}$ of crushed coke $(-2 \mathrm{~mm}+0.5 \mathrm{~mm})$ were added directly to the top surface of $164 \mathrm{~g}$ of liquid iron 2 mass pct carbon alloy. The liquid iron plus coke were held at temperature for a period of time ranging from 5 to 150 minutes. Afterward, the crucible containing the liquid iron and coke was quenched by lowering it into a water-cooled stainless steel quenching chamber fitted to the bottom of the furnace. The experiment, including the quenching, was carried out in a dry argon atmosphere. The argon gas flow rate during the experiment was $0.94 \mathrm{~L} / \mathrm{min}$ and was increased to $9.4 \mathrm{~L} / \mathrm{min}$ during quenching. After quenching, the samples were sectioned and prepared for electro-optical examination. As with the dissolution experiments, the quenched experiments were conducted at $1773 \mathrm{~K}\left(1500{ }^{\circ} \mathrm{C}\right)$ with liquid iron containing different initial sulfur concentrations. A schematic of the furnace and sample configuration is given in Figure 1. A schematic comparison of the samples used in both series of experiments is given in Figure 2. Additional details of the experimental method, raw materials, and sample preparation are available elsewhere. ${ }^{[4,5]}$

Carbon and sulfur analysis was performed using a LECO CS-444 analyzer (LECO Corporation; Saint Joseph, MI), whereas other elemental analysis of the iron was performed by atomic emission spectroscopic methods in the metallurgical laboratories of BlueScope Steel Ltd. (Port Kembla, Australia, and Spectrolab M8; Spectro Analytical Instruments, Kleve, Germany).

\section{Raw materials}

The iron carbon alloy was prepared in situ before the carburizer was added by melting appropriate amounts of electrolytic iron and coarsely crushed spectrographicgrade graphite rod and iron(II) sulfide powder to achieve a 2 pct carbon-iron alloy with a nominal sulfur level of 0.006 pet (no FeS), 0.03 pct, and 0.05 pct prior to the addition of the coke. The iron alloy compositions used in this study are given in Table I. Melting was achieved by heating the iron and graphite to $1813 \mathrm{~K}$ $\left(1540^{\circ} \mathrm{C}\right)$ for 10 minutes before cooling to the experimental temperature of $1773 \mathrm{~K}\left(1500^{\circ} \mathrm{C}\right)$.

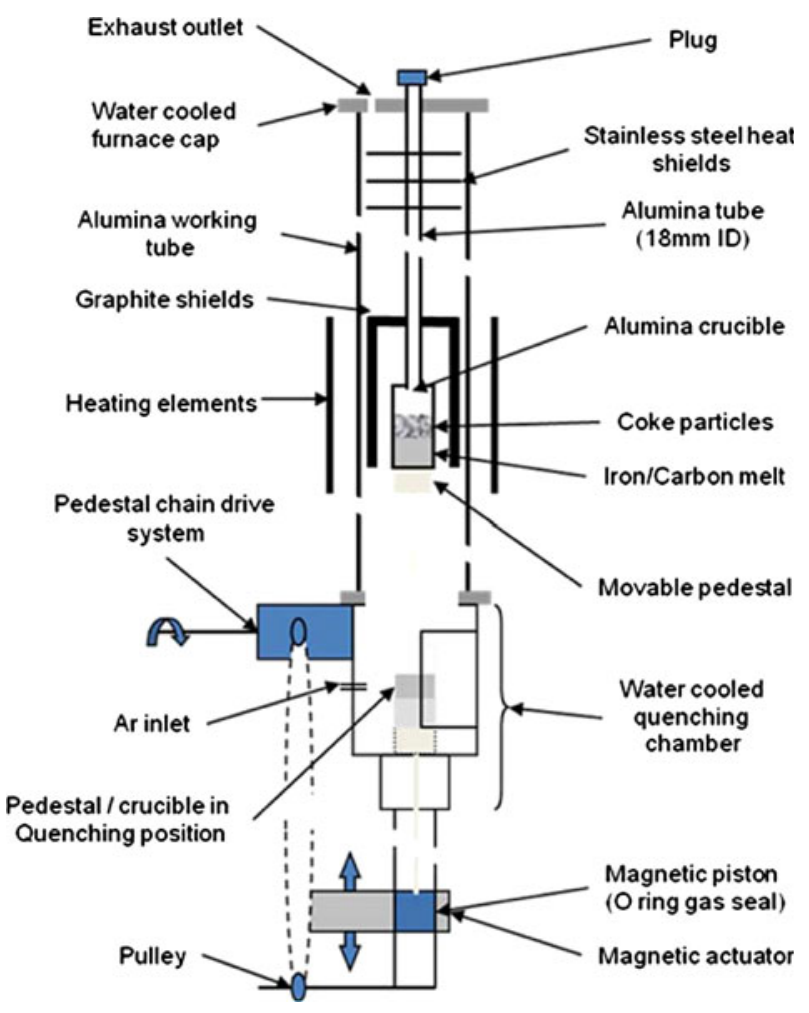

Fig. 1-Schematic of furnace configuration used in the quenched coke dissolution experiments. 


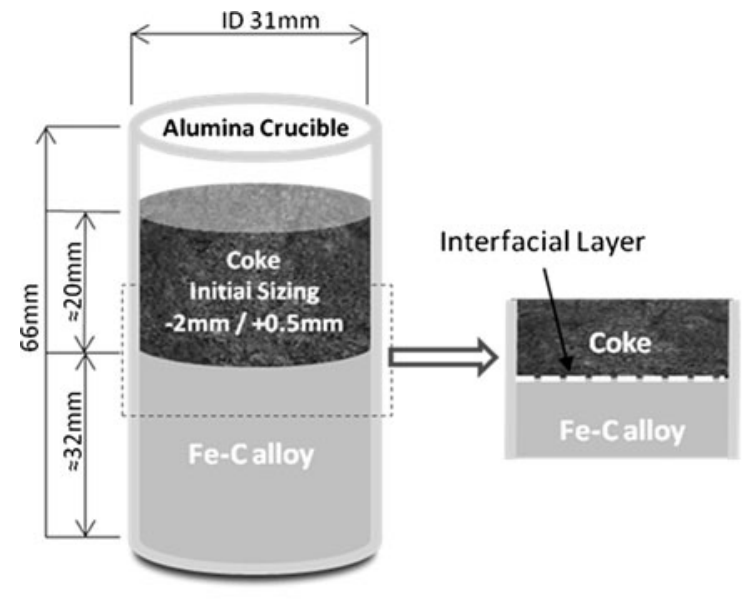

(a)

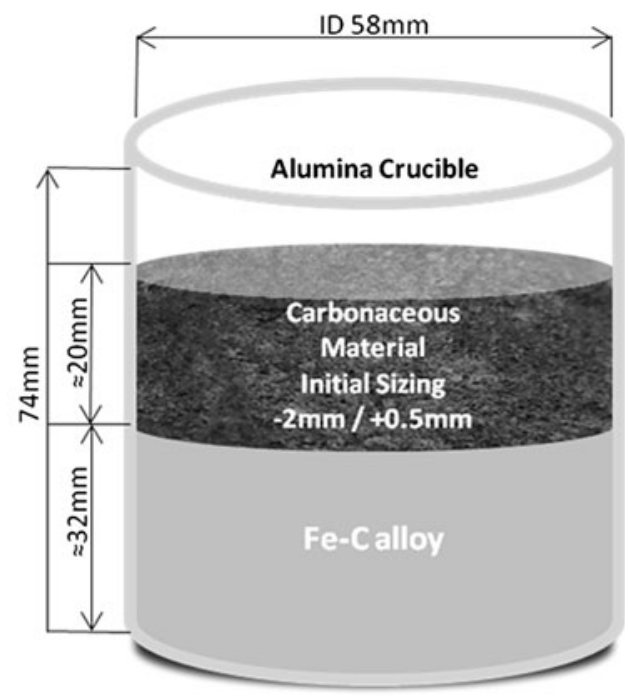

(b)

Fig. 2-Schematic showing experimental samples used for $(a)$ quenched coke dissolution experiments and $(b)$ coke dissolution experiments.

Table I. Initial Iron Alloy Compositions in Mass Pct and Carbon Saturation Value at $1773 \mathrm{~K}\left(1500{ }^{\circ} \mathrm{C}\right)$

\begin{tabular}{lccccc}
\hline$[\mathrm{C}]$ & {$[\mathrm{S}]$} & {$[\mathrm{Si}]$} & {$[\mathrm{Ti}]$} & {$[\mathrm{Mn}]$} & {$[\mathrm{C}]_{\text {sat } 1500}{ }^{[24]}$} \\
\hline 2.01 & 0.006 & & & & 5.17 \\
2.03 & 0.032 & 0.04 & 0.029 & 0.03 & 5.13 \\
2.04 & 0.049 & & & & 5.12 \\
\hline
\end{tabular}

Table II. Composition of the Oxide Components of the Mineral Matter Present in the Coke in Mass Pct

\begin{tabular}{lcccc}
\hline $\mathrm{SiO}_{2}$ & $\mathrm{Al}_{2} \mathrm{O}_{3}$ & $\mathrm{Fe}_{2} \mathrm{O}_{3}$ & $\mathrm{CaO}$ & $\mathrm{P}_{2} \mathrm{O}_{5}$ \\
\hline 54.8 & 32.3 & 4.9 & 2.9 & 1.42 \\
\hline $\mathrm{MgO}$ & $\mathrm{K}_{2} \mathrm{O}$ & $\mathrm{TiO}_{2}$ & $\mathrm{Na}_{2} \mathrm{O}$ & $\mathrm{Mn}_{3} \mathrm{O}_{4}$ \\
\hline 1.0 & 0.51 & 1.4 & 0.38 & 0.05 \\
\hline
\end{tabular}

The coke samples used were provided by BlueScope Steel and contained approximately 0.4 to 0.45 mass pct sulfur, 1.5 pet volatile matter, and 11.6 mass pet inorganic mineral matter. The inorganic mineral matter principally consisted of oxides that could be considered refractory in nature. A detailed oxide composition, measured by X-ray fluorescence, of the residue after combustion in air at $1088 \mathrm{~K}\left(815^{\circ} \mathrm{C}\right)$ is given in Table II.

The lump coke was coarsely crushed to $-20 \mathrm{~mm}$ in a jaw crusher, and then was crushed again in a roll crusher to obtain the desired $-2-\mathrm{mm}+0.5-\mathrm{mm}$ size fraction used. The 2-mm maximum size was selected to minimize any effects on coke dissolution caused by the presence of large cracks and fissures present in coke, whereas the $0.5-\mathrm{mm}$ minimum size prevents the coke from being entrained in the furnace exhaust gas stream when added.

Immediately prior to use, the coke was dried by heating it to $383 \mathrm{~K}\left(110^{\circ} \mathrm{C}\right)$ for 60 minutes. After drying, the coke was subjected to a roughing vacuum and purged with argon to minimize the amount of entrained air entering the furnace with the coke.

\section{Quenched sample preparation}

The crucibles containing the iron alloy and coke from the quenched experiments were impregnated with a liquid resin under vacuum to preserve the coke-metal interface during sectioning. The bottom section of the crucible was removed and iron samples were machined from the iron block for analysis. A vertical cut was made across the center of the sample exposing the coke-metal interface. The sample was mounted in epoxy resin and prepared for scanning electron microscopy (SEM) analysis.

\section{Assessment of interfacial mineral layer}

SEM analysis, involving electro-optical imaging, $\mathrm{X}$-ray mapping, and energy-dispersive spectroscopy (EDS) analysis performed over large areas of the coke-iron interface from the quenched series of experiments. It was assumed that the condition of the solidified interfacial region was representative of the high-temperature phenomena occurring at the cokeiron interface immediately prior to quenching. The reported mineral matter compositions are derived from EDS analysis of the quenched samples.

\section{RESULTS/DISCUSSION}

\section{A. Mineral Layer Formation and Its Effect on Dissolution Kinetics}

The carbon dissolution kinetics and the mineral layer formation in the system studied have been discussed in detail elsewhere. ${ }^{[4,5]}$ What follows is a brief summary of the mineral layer formation as presented in these articles and new data relating to sulfur in the liquid iron as well 
as its influence on the kinetics of carbon dissolution and sulfide formation not previously presented.

For the system being studied, it has been established that, as the coke dissolution reaction proceeds, a mineral layer was formed at the coke-iron interface. This mineral layer primarily consisted of alumina and the calcium aluminates $\mathrm{CA} 6, \mathrm{CA} 2$, and $\mathrm{CA}$, where $\mathrm{C}$ represents $\mathrm{CaO}$ and $\mathrm{A}$ represents $\mathrm{Al}_{2} \mathrm{O}_{3}$.

Furthermore, it has been established that the predominant structure of this layer changes from a loose agglomerate of mostly alumina particles to an open porous network of acicular particles (needles). The needles remain alumina rich but now contain calcium oxide in the form of CA6. Continued dissolution of the coke increases the calcium enrichment of the layer. During this calcium enrichment, the layer retains a relatively open structure as the fine CA6 needles are progressively replaced by a coarser CA2 structure. However, additional calcium enrichment of the layer, and the appearance of the CA phase is accompanied by densification of the mineral layer.

It also was observed that the change from an open to a dense layer coincides with significant slowing of the rate of coke dissolution in iron. It was argued ${ }^{[4]}$ that formation of the dense layer inhibits carbon transfer to the liquid iron by reducing the contact area between the coke and the iron.

It should be noted, however, that, as coke dissolves in iron, mineral phases present within the coke are being exposed and interact with the existing mineral layer and the liquid iron. This exposure results in a phase and concentration gradient in the layer at all experimental times. Therefore, although, for example, a CA2/CA layer might be predominant, it is expected that the layer will contain some quantity of calcium aluminates that are lower in calcium (e.g., CA6) and alumina as well as a potentially small quantity of calcium aluminates that are higher in calcium (e.g., C12A7), although no evidence of any liquid phase being present at the iron-coke interface was observed in quenched samples. The concept of layer development is well illustrated in Figure 3.

Although the predominant phases present in the mineral matter layers shown in Figures 3 through 6 are alumina and calcium based, evidence also was found of sulfide formation contributing to the interfacial mineral layer. The sulfide layer formed exclusively on the iron side of the interface. It is assumed that the observed sulfide phase is primarily calcium sulfide CaS. The basis for this assumption is that sulfur, where evident in Figures 4 through 6 , is associated with the calcium in the X-ray maps, not the aluminum or iron.

As indicated in Table III, the appearance of the sulfide phase that contributes to the mineral layer is delayed until approximately 40 minutes after the coke is added to the liquid iron. Before this time, although discrete sulfide particles are sometimes found in the mineral layer, the mineral layer is essentially free of sulfur. The observed discrete particles are not necessarily on the iron side of the interface and are typically associated with aluminum and silicon as well as calcium. Discrete sulfide mineral particles are present in the unreacted coke. Their initial presence at the interface is explained most readily by their exposure as a result of dissolution of the coke's carbonaceous matrix rather than a reaction leading to the development of a sulfide layer at the interface.

As indicated in Table III, once the sulfide layer had formed after approximately 40 minutes, the proportion of sulfide in the mineral layer increased with increased experimental time and the initial sulfur concentration of the liquid iron. Typical images of the coke-iron interface depicting the increasing proportion of sulfide in the
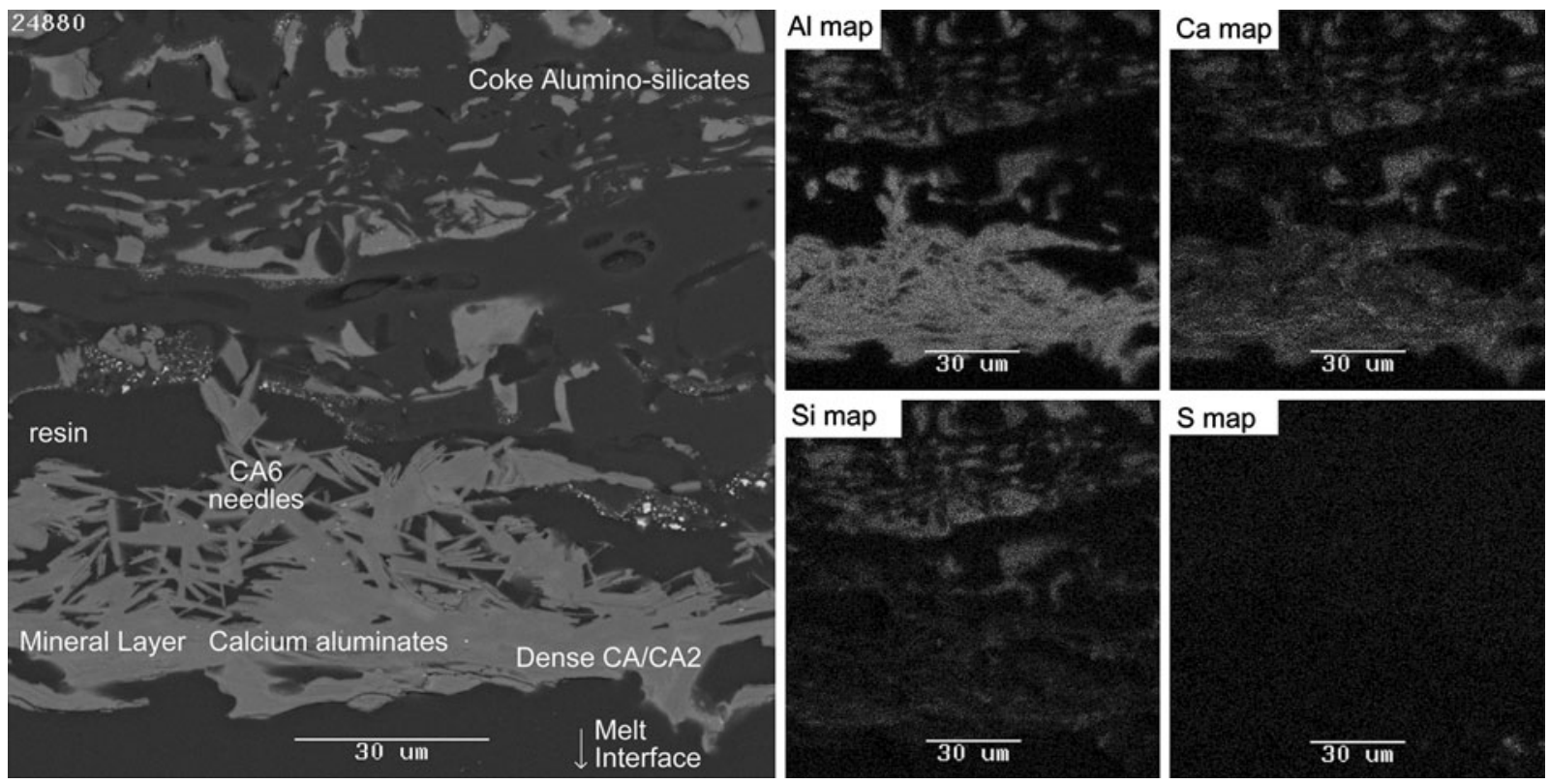

Fig. 3-Mineral layer at $1773 \mathrm{~K}\left(1500{ }^{\circ} \mathrm{C}\right)$ and 10 min showing composition and phase gradient through a section of the mineral layer. The scale bar is $30 \mu \mathrm{m}$ and $[\mathrm{S}]_{\mathrm{o}}=0.006$ mass pet. 

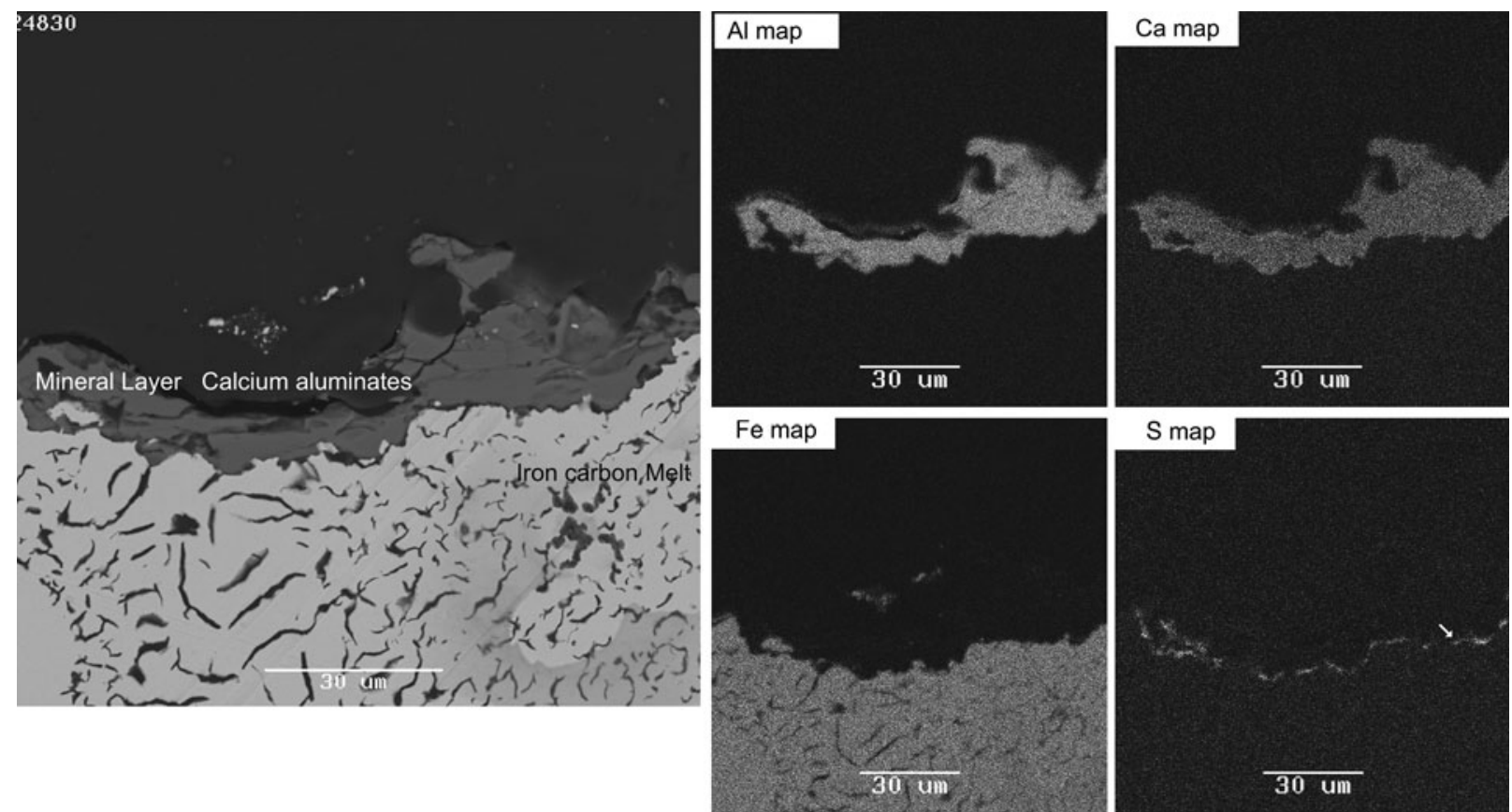

Fig. 4-SEM and X-ray maps of mineral layer showing a "fine sulfide layer" at $1773 \mathrm{~K}\left(1500^{\circ} \mathrm{C}\right)$ Quenched after $60 \mathrm{~min}$ for $[\mathrm{S}]_{\mathrm{o}}=0.006$ mass pct. The scale bar is $30 \mu \mathrm{m}$.
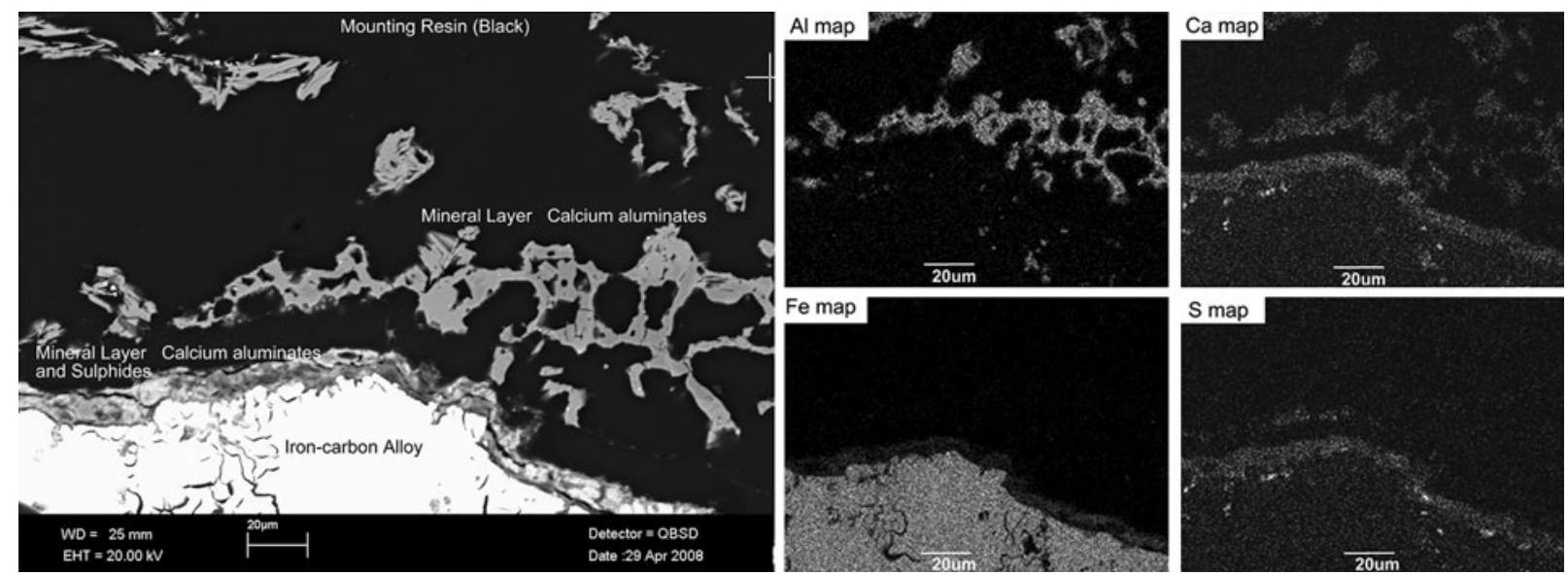

Fig. 5-SEM and X-ray maps of mineral layer showing a "thick sulfide layer" at $1773 \mathrm{~K}\left(1500{ }^{\circ} \mathrm{C}\right)$ Quenched after 90 min for $[\mathrm{S}]_{\mathrm{o}}=0.03$ mass pct. The scale bar is $20 \mu \mathrm{m}$.

mineral layer and the progression from a fine layer of sulfide, to a continuous thicker sulfide layer, to a sulfide layer that has significantly replaced the original calcium aluminate layer are shown in Figures 4 through 6.

\section{B. Carbon Transfer}

Carbon pick-up from coke in the liquid iron under the three different initial sulfur levels is shown in Figure 7 for both the dissolution series and the quenched series of experiments. Good agreement is noted in the level of carbon pick-up with time between the two experimental methods employed in this study. This agreement indicates that the same factors affecting the carbon transfer from coke to iron are active in both sets of experiments.
It is apparent from the data presented in Figure 7 that the increased initial sulfur level in the liquid iron decreased the carbon transfer from the coke to the iron. This finding is consistent with most other studies on coke dissolution into iron. ${ }^{[13,15-23]}$

\section{Coke Dissolution Kinetics}

Coke dissolution into iron is generally described as being limited by liquid-phase mass transfer of carbon in iron. The mass-transfer coefficient $k_{m}$ for such a process can be found from the slope of a plot of the left-hand side of Eq. [1] against time. Plots for the coke dissolution data with the initial sulfur levels of $0.006,0.03$, and 0.05 mass pct are given in Figure 8. The straight lines in 

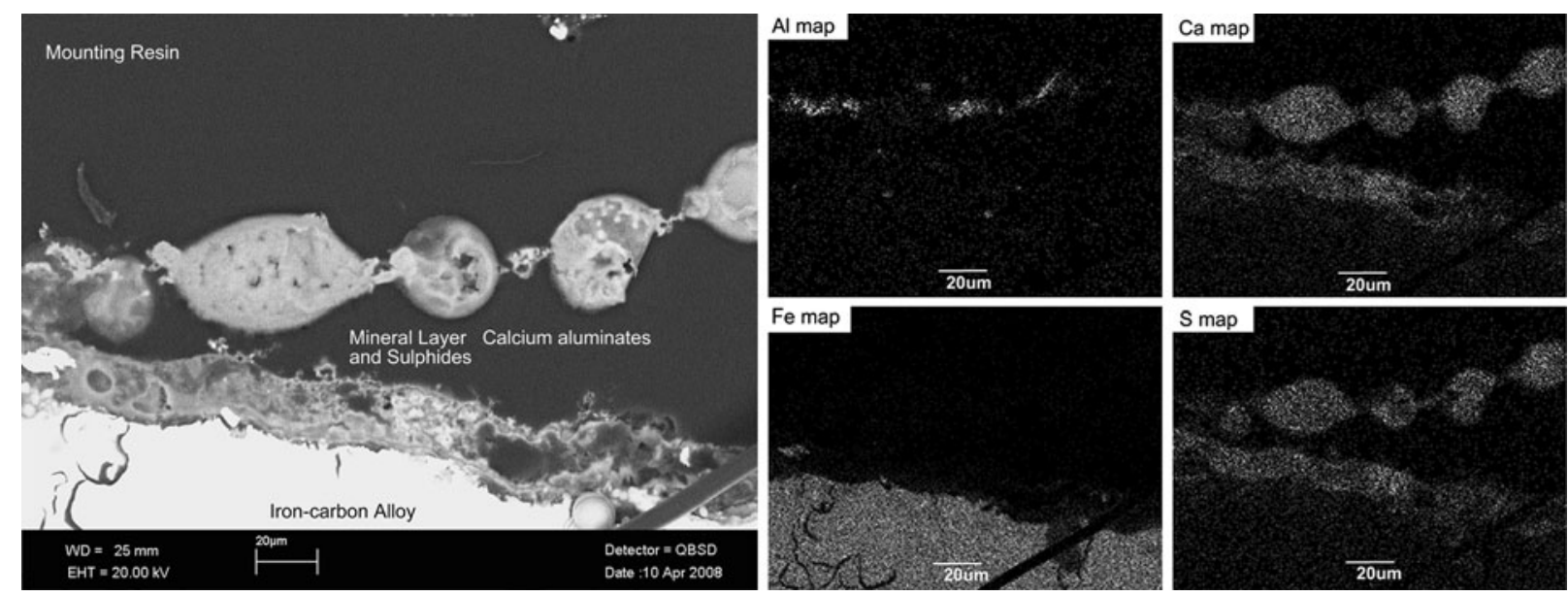

Fig. 6-SEM and X-ray maps of mineral layer showing a "thick sulfide layer replacing the original calcium aluminate layer" at $1773 \mathrm{~K}$ $\left(1500{ }^{\circ} \mathrm{C}\right)$. Quenched after $90 \mathrm{~min}$ for $[\mathrm{S}]_{\mathrm{o}}=0.05$ mass pct. The scale bar is $20 \mu \mathrm{m}$.

Table III. Observations of the Mineral Layer Formed at the Coke-Iron

\begin{tabular}{|c|c|c|c|c|c|c|}
\hline \multirow[b]{2}{*}{$\begin{array}{l}\text { Dissolution } \\
\text { Time (min) }\end{array}$} & \multicolumn{2}{|c|}{$[\mathrm{S}]_{\mathrm{o}} *=0.006$ Mass Pct } & \multicolumn{2}{|c|}{$[S]_{\mathrm{o}}=0.03$ Mass Pct } & \multicolumn{2}{|c|}{$[\mathrm{S}]_{\mathrm{o}}=0.05$ Mass Pct } \\
\hline & $\begin{array}{c}\text { Predominant } \\
\text { CAx Phases } \\
\text { Observed }\end{array}$ & $\begin{array}{c}\text { Observations } \\
\text { of Sulfide } \\
\text { Layer }\end{array}$ & $\begin{array}{c}\text { Predominant } \\
\text { CAx Phases } \\
\text { Observed }\end{array}$ & $\begin{array}{c}\text { Observations } \\
\text { of Sulfide } \\
\text { Layer }\end{array}$ & $\begin{array}{c}\text { Predominant } \\
\text { CAx Phases } \\
\text { Observed }\end{array}$ & $\begin{array}{l}\text { Observations } \\
\text { of Sulfide Layer }\end{array}$ \\
\hline 5 & $\mathrm{~A}+\mathrm{CA} 6$ & $\mathrm{No}^{*}$ & $\ldots^{\dagger}$ & - & - & - \\
\hline 10 & $\mathrm{CA} 6+\mathrm{CA} 2$ & $\mathrm{DP}^{\S}$ & $\mathrm{CA} 6+\mathrm{CA} 2$ & No & $\mathrm{CA} 6+\mathrm{CA} 2$ & No \\
\hline 30 & $\mathrm{CA} 6+\mathrm{CA} 2$ & DP & $\mathrm{CA} 6+\mathrm{CA} 2$ & DP & $\mathrm{CA} 6+\mathrm{CA} 2$ & DP \\
\hline 40 & $\mathrm{CA} 2+\mathrm{CA}$ & $\mathrm{FL}^{\top}$ & $\mathrm{CA} 2+\mathrm{CA}$ & FL & $\mathrm{CA} 2+\mathrm{CA} 6$ & FL \\
\hline 60 & $\mathrm{CA} 2+\mathrm{CA}$ & FL & $\mathrm{CA} 2+\mathrm{CA}$ & FL & $\mathrm{CA} 2+\mathrm{CA}$ & $\mathrm{TL}^{* *}$ \\
\hline 90 & $\mathrm{CA} 2+\mathrm{CA}$ & FL & $\mathrm{CA} 2+\mathrm{CA}$ & TL & $\mathrm{CA} 2+\mathrm{CA}$ & $\mathrm{VTL}^{\dagger \dagger}$ \\
\hline 120 & $\mathrm{CA} 2+\mathrm{CA}$ & TL & $\mathrm{CA} 2+\mathrm{CA}$ & - & - & - \\
\hline 150 & $\mathrm{CA} 2+\mathrm{CA}$ & TL & $\mathrm{CA} 2+\mathrm{CA}$ & VTL & - & - \\
\hline
\end{tabular}

* $[\mathrm{S}]_{\mathrm{o}}$ is initial liquid iron sulfur concentration.

${ }^{\dagger}$ - is no sample obtained.

${ }^{\star}$ No is no sulfide observed.

${ }^{\S} \mathrm{DP}$ is discrete sulfide particles observed.

${ }^{\top} \mathrm{FL}$ is a fine sulfide layer observed on iron side of the coke-iron interface.

**TL is a thick continuous sulfide layer observed on iron side of the coke-iron interface.

${ }^{\dagger}$ VTL is a thick continuous sulfide layer observed at the coke - iron interface and that the calcium aluminate layer has been significantly replaced by the sulfide layer.

Figure 8 represent linear regions of the plot, the slopes of which are graphical representations of the rate constant $k_{m}(\mathrm{~m} / \mathrm{s})$. Equation [1] is expressed as follows:

$$
\frac{V}{A} \ln \left[\frac{[C]_{\mathrm{sat}}-[C]_{\mathrm{o}}}{[C]_{\mathrm{sat}}-[C]_{\mathrm{bulk}}}\right]=k_{m} t
$$

where $V\left(\mathrm{~m}^{3}\right)$ is the liquid iron volume, $A\left(\mathrm{~m}^{2}\right)$ is the contact area between the iron and the coke, and $[C]_{\text {sat }}$ is the carbon saturation level in iron in mass pctcalculated using the initial iron alloy compositions and the thermochemical software package MTDATA ${ }^{[24]}$ and reported in Table $\mathrm{I}$. $[\mathrm{C}]_{\mathrm{o}}$ is the initial carbon level in iron in mass pct, $[\mathrm{C}]_{\text {bulk }}$ is the bulk carbon level in liquid iron in mass pct, and $t$ is time.

Figure 8 , shows that a significant change occurs in $k_{m}$, the rate constant, after a period of time for all initial sulfur levels. The change in $k_{m}$, a decrease in the slope, represents a decrease in the rate of coke (carbon) dissolution into the iron. The change in $k_{m}$ has been interpreted as a change in the kinetic regime controlling the dissolution of carbon from the coke.

Previously published results for the low initial sulfur concentrations in iron $\left([\mathrm{S}]_{\mathrm{o}}=0.006 \mathrm{pct}\right)^{[4,5]}$ indicated that the dissolution reaction had effectively stopped after the densification of the mineral layer at $1773 \mathrm{~K}$ $\left(1500{ }^{\circ} \mathrm{C}\right)$, indicated by a flattening of the second stage of the plot. This change in $k_{m}$ was explained in terms of changes in the available contact area between the coke and the iron as the mineral layer developed and its morphology changed, ${ }^{[4]}$ However, Figure 8 represents significantly more data, (aggregated data for two runs) and longer timescales than previously presented. Reevaluation of the carbon dissolution rates for the low initial 


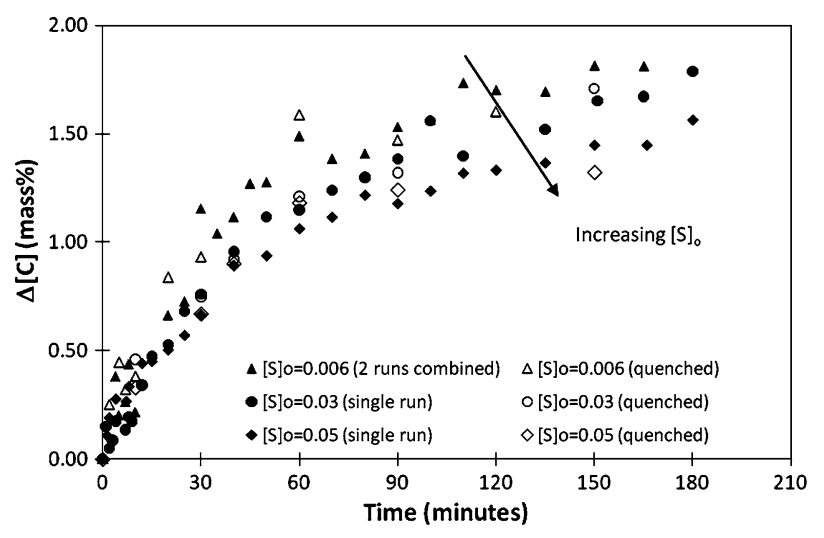

Fig. 7-Carbon pick-up vs time for quenched and nonquenched coke dissolution at $1773 \mathrm{~K}\left(1500{ }^{\circ} \mathrm{C}\right)$.

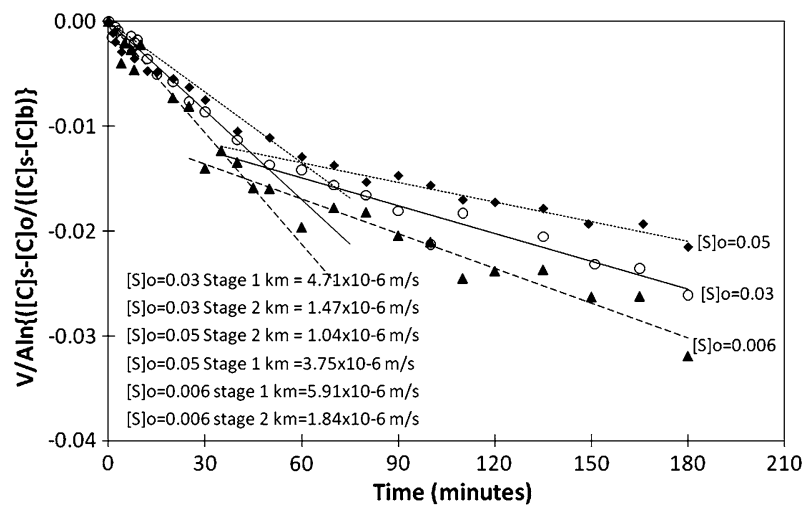

Fig. 8-Mass-transfer control plots for coke dissolution at $1773 \mathrm{~K}$ $\left(1500{ }^{\circ} \mathrm{C}\right)$ and various initial sulfur in iron levels.

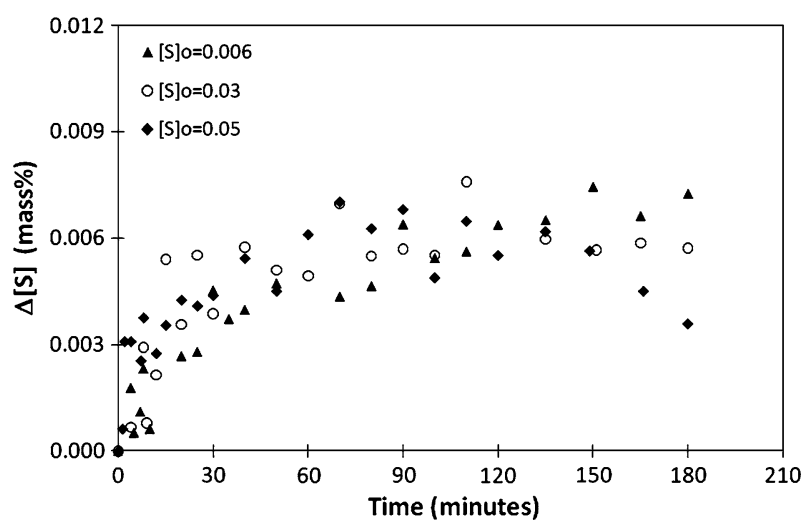

Fig. 9- Sulfur concentration in the metal as a function of dissolution time at $1773 \mathrm{~K}\left(1500^{\circ} \mathrm{C}\right)$. sulfur concentration experiments at $1773 \mathrm{~K}\left(1500{ }^{\circ} \mathrm{C}\right)$ with this new data indicated that, although the reaction slowed, it did not stop.

The time at which the change in the rate constant $k_{m}$ occurs increased with an increased initial sulfur level. The change in kinetic regimes occurred at approximately 40 to 45 minutes for the low sulfur alloy, increasing to approximately 50 and 60 minutes for the 0.03 and 0.05 mass pct $\mathrm{S}$ alloys, respectively. However, the carbon levels at which the change occurs was relatively constant, at $3.13,3.15$, and 3.10 mass pct, respectively. Thus, the amounts of carbon dissolved from the coke are similar for each iron alloy. Therefore, the amount of mineral matter exposed to the coke-metal interface is expected to be similar at the point of change, and thus, the mineral layer should be similar both in terms of composition and structure. This similarity was observed in the SEM analysis of the mineral layer at the three different sulfur levels as presented in Table III.

\section{Sulfur Transfer}

Sulfur transfer to the liquid iron as a function of time can be inferred from Figure 9. The sulfur transferred to the iron is derived solely from the coke. Work done by Cham et al. ${ }^{[3]}$ found that under these conditions the rate of sulfur transfer is related to the amount of coke dissolved and thus to carbon transfer. If this is true, then it can be expected that sulfur pick-up could be expressed as the following mass pet ratio:

$$
\text { Mass pet ratio }=\frac{\Delta(\operatorname{pct} S)}{\Delta(\operatorname{pct} C)}
$$

From the coke used in this study, the ratio would be in the range of 0.0045 to 0.0051 . However, at least two distinct carbon-transfer (kinetic) regimes are present in the system being studied, and these regimes have a significant effect on the carbon dissolution from the coke. The early fast carbon-transfer kinetic regime with an open mineral layer structure is referred to as stage I. The later and slow carbon-transfer kinetic regime with a dense mineral layer is referred to as stage II. In the $[S]_{\mathrm{o}}=0.05$ pct iron, a drop occurs in the sulfur concentration at times greater than approximately 120 minutes. This finding also will be examined in the context of the mineral layer formation. The sulfur pickup in the iron per mass pct carbon pick-up, for stage I and II, has been calculated and is given in Table IV. The values for sulfur pick-up at the change in kinetic regimes is an average of three samples (from the dissolution series of experiments), using the iron composition at the

Table IV. The Liquid Iron Sulfur Pick-Up and Mass Pct Ratio (Eq. [2]) Values for Stage I and Stage II

\begin{tabular}{|c|c|c|c|c|c|c|}
\hline \multirow[b]{2}{*}{$(\text { Pct S })_{\mathrm{o}}$} & \multicolumn{3}{|c|}{ Stage I } & \multicolumn{3}{|c|}{ Stage II } \\
\hline & $\Delta(\operatorname{Pct} \mathrm{C})$ & $\Delta($ Pct S $)$ & Mass Pct Ratio & $\Delta($ Pct C $)$ & $\Delta($ Pct S $)$ & Mass Pct Ratio \\
\hline 0.006 & 1.12 & 0.005 & 0.0045 & 0.77 & 0.002 & 0.0026 \\
\hline 0.03 & 1.12 & 0.005 & 0.0045 & 0.58 & 0.000 & 0.0000 \\
\hline 0.05 & 1.06 & 0.006 & 0.0057 & 0.42 & -0.001 & -0.0023 \\
\hline
\end{tabular}


time closest to the change in kinetic regimes and that of the samples before and after. The values for the final iron carbon and sulfur are those of the average values for the last three samples taken at 150, 165, and 180 minutes.

It is apparent from the mass pct ratio (Eq. [2]) that, during the initial stage of coke dissolution (stage I), sulfur transfer to the iron closely matches the expected pick-up based on a simple mass balance based on carbon transfer. However, as the mineral layer develops (stage II) and becomes richer in calcium, the simple mass balance based on carbon transfer breaks down as the expected sulfur in the iron is not observed. This "missing" sulfur is observed in the mineral layer and generally only at the iron side of the mineral layer. It is not clear whether the sulfide formed at the iron side of the mineral layer formed directly or after dissolution followed by desulfurization. The dropping off of $[\mathrm{S}]$ in Figure 9 for the high $[\mathrm{S}]_{\mathrm{o}}$ iron late in the experiment is supportive of the desulfurization mechanism, but not definitive. Regardless of the sulfide formation layer mechanism, it is clear from Table III and the micrographs that the conditions at the mineral layeriron interface, when higher calcium aluminates are present - particularly the CA phase - promote calcium sulfide formation.

\section{E. Thermodynamic Considerations}

Employing relevant thermodynamic data on the activity of calcium oxide $a_{\langle\mathrm{CaO}\rangle}$ to represent changes in the mineral layer as it develops through the range of calcium aluminates observed, sulfide layer formation, (assumed to be $\langle\mathrm{CaS}\rangle$ formation) can be represented as follows:

$$
\langle\mathrm{CaO}\rangle+[\mathrm{S}]=\langle\mathrm{CaS}\rangle+[\mathrm{O}]
$$

where \langle\rangle and [ ] represent solid and in solution in the liquid iron, respectively. The Gibbs free energy for Eq. [3], under the prevailing experimental conditions found at the mineral layer-iron interface, can be analyzed with the following equation:

$$
\Delta G=\Delta G^{\circ}+\mathrm{R} T \ln \left(\frac{a_{\langle\mathrm{CaS}\rangle} h_{[\mathrm{O}]}}{a_{\langle\mathrm{CaO}\rangle} h_{[\mathrm{S}]}}\right)
$$

where $\Delta G^{\circ}$ is the standard Gibbs free energy, $T$ is the temperature in $\mathrm{K}, \mathrm{R}$ is the gas constant, and $a$ and $h$ are activities of the species based on a pure reference and Henrian 1 weight pct reference states, respectively.

The following equation is used to calculate the $\Delta G^{\circ}$ and was obtained using the Gibbs free energy relations in Table V:

$$
\Delta G^{\circ}=371,510-199.36 \mathrm{~T} \mathrm{~J} / \mathrm{mol}
$$

The $a\langle\mathrm{CaO}\rangle$ in Eq. [4] for the calcium aluminates was obtained from MTDATA, ${ }^{[24]}$ using $\langle\mathrm{CaO}\rangle$ as a reference state, and is given in Figure 10.

The $\Delta G$ in Eq. [4] has been calculated for three experimental conditions (compositions) for each $[\mathrm{S}]_{\mathrm{o}}$ studied. The first condition is the initial iron alloy
Table V. Tabulated Thermodynamic Data ${ }^{[25]}$

\begin{tabular}{ll}
\hline Reaction & Gibbs Free Energy $\left(\mathrm{J} \mathrm{mol}^{-1}\right)$ \\
\hline $1 / 2\left(\mathrm{O}_{2}\right)=[\mathrm{O}]^{*}$ & $\Delta G^{\circ}=-115,750-4.63 \mathrm{~T}$ \\
$1 / 2\left(\mathrm{~S}_{2}\right)=[\mathrm{S}]$ & $\Delta G^{\circ}=-135,060+23.43 \mathrm{~T}$ \\
$\langle\mathrm{C}\rangle_{\text {graphite }}=[\mathrm{C}]$ & $\Delta G^{\circ}=22,594-42.26 \mathrm{~T}$ \\
$\{\mathrm{Ca}\}+1 / 2\left(\mathrm{O}_{2}\right)=\langle\mathrm{CaO}\rangle$ & $\Delta G^{\circ}=-900,300+275.1 \mathrm{~T}$ \\
$\{\mathrm{Ca}\}+1 / 2\left(\mathrm{~S}_{2}\right)=\langle\mathrm{CaS}\rangle$ & $\Delta G^{\circ}=-548,100+103.8 \mathrm{~T}$ \\
$\langle\mathrm{C}\rangle_{\text {graphite }}+1 / 2\left(\mathrm{O}_{2}\right)=(\mathrm{CO})$ & $\Delta G^{\circ}=-114,400-85.8 \mathrm{~T}$ \\
{$[\mathrm{C}]+[\mathrm{O}]=(\mathrm{CO})$} & $\Delta G^{\circ}=-21,244-38.91 \mathrm{~T}$ \\
\hline
\end{tabular}

$*()$ and \{\} represent gas and liquid state.

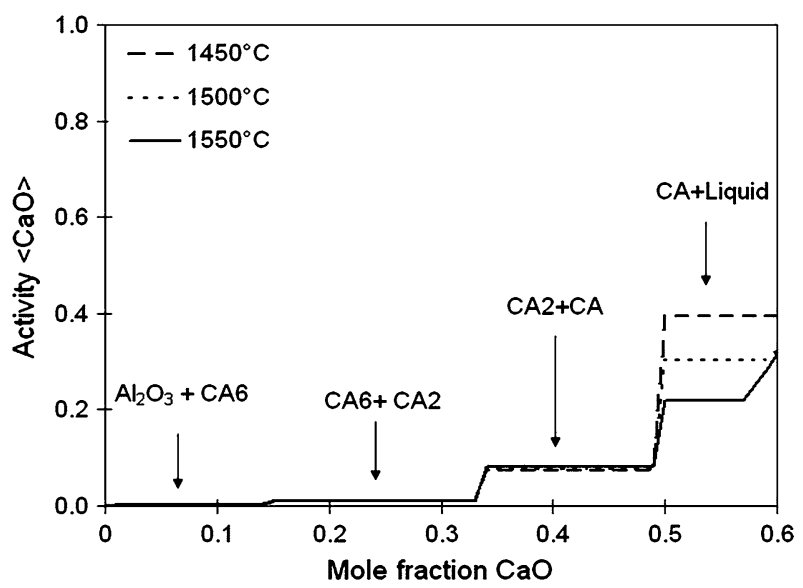

Fig. 10-The activity of $\langle\mathrm{CaO}\rangle$ as calculated using MTDATA. ${ }^{[24]}$

composition. The second condition is the iron alloy composition after 30 minutes. This condition corresponds to a period when the mineral layer is predominately the CA2 calcium aluminate. The third condition is based on the iron alloy composition at the onset of stage II, when the carbon dissolution starts to slow. This period is also when the formation of the calcium aluminate CA is observed. The iron alloy compositions used are given in Table VI. The $\Delta G$ values calculated from Eq. [4] are given in Figure 11. Negative $\Delta G$ values indicate that $\langle\mathrm{CaS}\rangle$ formation is thermodynamically favored, whereas a positive value indicates its formation of is not thermodynamically favored under the experimental conditions.

The calculations presented in Figure 11 were made assuming that the $\langle\mathrm{CaS}\rangle$ was pure and therefore had an activity of 1 and that the [S] showed an ideal Henrian behavior. The value of $h_{[\mathrm{O}]}$ was calculated from the Gibbs free energy of reaction for the following equation, assuming $p_{\mathrm{co}}=1 \mathrm{~atm}$ and the carbon activity calculated from the liquid iron composition ${ }^{[26]}$ :

$$
[\mathrm{C}]+[\mathrm{O}]=(\mathrm{CO})
$$

In Figure 11, the shading represents the calcium aluminates that are observed experimentally at the coke-iron interface for the three conditions (compositions) considered. Figure 11 shows that, under the prevailing experimental conditions for all $[\mathrm{S}]_{\mathrm{o}}$, that sulfide formation is favored when CA is present in the mineral layer. This analysis of the $\Delta G$ for Eq. [4] is 
Table VI. Liquid Iron Compositions for Three Different Experimental Conditions

\begin{tabular}{|c|c|c|c|c|c|c|c|c|c|}
\hline \multirow[b]{2}{*}{ Condition } & \multicolumn{3}{|c|}{$[S]_{\mathrm{o}}=0.006$} & \multicolumn{3}{|c|}{$[\mathrm{S}]_{\mathrm{o}}=0.03$} & \multicolumn{3}{|c|}{$[\mathrm{S}]_{\mathrm{o}}=0.05$} \\
\hline & 1 & 2 & 3 & 1 & 2 & 3 & 1 & 2 & 3 \\
\hline [C] (mass pct) & 2.01 & 3.05 & 3.13 & 2.03 & 2.79 & 3.15 & 2.04 & 2.70 & 3.10 \\
\hline [S] (mass pct) & 0.006 & 0.010 & 0.011 & 0.032 & 0.036 & 0.037 & 0.049 & 0.054 & 0.055 \\
\hline $\begin{array}{l}\text { Predominant } \\
\text { mineral } \\
\text { layer phases }\end{array}$ & $\mathrm{A}+\mathrm{CA} 6$ & $\mathrm{CA} 2+\mathrm{CA} 6$ & $\mathrm{CA} 2+\mathrm{CA}$ & $\mathrm{A}+\mathrm{CA} 6$ & $\mathrm{CA} 2+\mathrm{CA} 6$ & $\mathrm{CA} 2+\mathrm{CA}$ & $\mathrm{A}+\mathrm{CA} 6$ & $\mathrm{CA} 2+\mathrm{CA} 6$ & $\mathrm{CA} 2+\mathrm{CA}$ \\
\hline
\end{tabular}

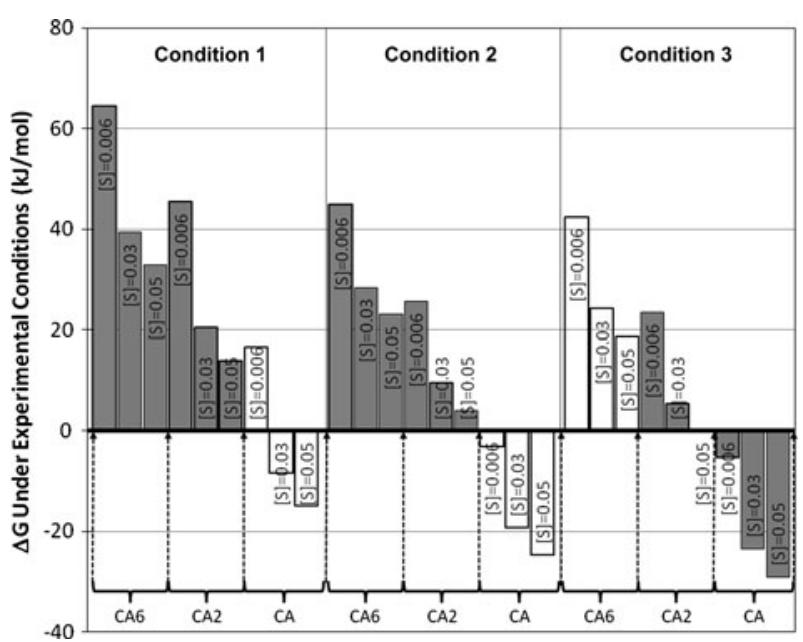

Fig. 11-Calculation of $\Delta G$ for the three experimental conditions for the different calcium aluminate phases. The shaded areas represent phases identified at the coke-iron interface from the quenching experiments.

consistent with the experimental observations as presented in Table III. For calculations of the 0.05 pct $[\mathrm{S}]_{\mathrm{o}}$ liquid iron in the third condition $3,\langle\mathrm{CaS}\rangle$ formation is also possible when CA2 is present. This finding is also consistent with the experimental observations given in Table III where a fine layer of sulfide was identified at 40 minutes in the presence of CA2 and CA6.

In other experimental works, such as the liquid iron on coke sessile drop measurements, ${ }^{[9-11,14]}$ a sulfide layer also was reported. This type of measurement necessitates a low iron-to-coke mass ratio that can cause large changes in the liquid-iron composition for short reaction times and little carbon and sulfur transfer. Because Figure 11 also shows that the liquid iron composition for all three conditions affects the sulfide stability, care must be taken when comparing sessile drop measurements with coke dissolution investigations such as those reported in this study.

\section{CONCLUSIONS}

In an experimental study on the effects of initial sulfur concentrations in liquid iron on mineral layer formation at the coke-iron interface during coke dissolution, a two-stage dissolution behavior was exhibited in the carbon transfer from coke to iron at low initial sulfur in iron levels as reported by the authors in a previous study. ${ }^{[4]}$ The mineral layer that formed at the interface was predominately a calcium aluminate that became progressively enriched with calcium. Furthermore, at times greater than approximately 40 minutes, and after the establishment of an enriched calcium aluminate layer formation, a sulfide layer formed at the iron side of this mineral layer. The composition of this sulfide layer indicates that it is principally a calcium sulfide layer.

Thermodynamic analysis of the experimental results confirmed that the calcium-enriched calcium aluminates formation was necessary to stabilize the calcium sulfide layer for the coke composition studied.

Furthermore, the addition of sulfur to the iron reduced the coke dissolution rate.

\section{REFERENCES}

1. Y.E. Omori: Blast Furnace Phenomena and Modelling, Elsevier Applied Science, London, U.K., 1987, pp. 57-58.

2. P. Loison, P. Foch, and A. Boyer: Coke Quality and Production, Butterworths, London, U.K., 1989, pp. 159-200.

3. S.T. Cham, V. Sahajwalla, R. Sakurovs, H. Sun, and M. Dubikova: ISIJ Int., 2004, vol. 44, pp. 1835-41.

4. M.W. Chapman, B.J. Monaghan, S.A. Nightingale, J.G. Mathieson, and R.J. Nightingale: Metall. Mater. Trans. B, 2008, vol. 39B, pp. 418-38.

5. M.W. Chapman, B.J. Monaghan, S.A. Nightingale, J.G. Mathieson, and R.J. Nightingale: SCANMET III, Lulea, Sweden, 2008, pp. 245-54.

6. M.W. Chapman, B.J. Monaghan, S.A. Nightingale, J.G. Mathieson, and R.J. Nightingale: Australia-China-Japan Symp. on Iron and Steelmaking, Liaoning Science and Technology Publishing House, China, 2006, pp. 90-96.

7. M.W. Chapman, B.J. Monaghan, S.A. Nightingale, J.G. Mathieson, and R.J. Nightingale: ISIJ Int., 2007, vol. 47, pp. 973-81.

8. H.W. Gudenau, J.P. Mulanza, and D.G.R. Sharma: Steel Res. Int., 1990, vol. 61, pp. 97-104.

9. R. Khanna, F. McCarthy, H. Sun, N. Simento, and V. Sahajwalla: Metall. Mater. Trans. B, 2005, vol. 36B, pp. 719-29.

10. F. McCarthy, R. Khanna, V. Sahajwalla, and N. Simento: ISIJ Int., 2005, vol. 45, pp. 1261-68.

11. F. McCarthy, V. Sahajwalla, J. Hart, and N. Saha-Chaudhury: Metall. Mater. Trans. B, 2003, vol. 34B, pp. 573-80.

12. M.B. Mourao, G.G.K. Murthy, and J.F. Elliott: Metall. Trans. B, 1993, vol. 24B, pp. 629-38.

13. S. Orsten and F. Oeters: Process Technology Proc, Iron and Steel Society, Washington, DC, 1986, pp. 143-55.

14. C. Wu, R. Wiblen, and V. Sahajwalla: Metall. Mater. Trans. B, 2000, vol. 31B, pp. 1099-1104.

15. S.O. Ericsson and P.O. Mellberg: Scand. J. Metall., 1981, vol. 10, pp. $15-18$.

16. S. Orsten and F. Oeters: W.O. Philbrook Memorial Symp. Proc., Iron and Steel Society, Toronto, Ontario, Canada, 1988, pp. 27-38. 
17. V.A. Grigoryan and V.P. Karshin: Izvest Akad Nauk Sssr Metally, 1972, vol. 1, pp. 78-81.

18. V. Sahajwalla, I.F. Taylor, and J.K. Wright: 52nd Ironmaking Conf., 1993, pp. 355-65.

19. Y. Shigeno, M. Tokuda, and M. Ohtani: Trans. Jpn. Inst. Met., 1985, vol. 26, pp. 33-43.

20. J.K Wright and B.R. Baldock: Metall. Trans. B, 1988, vol. 19B, pp. $375-82$.

21. J.K. Wright and I.F. Taylor: ISIJ Int., 1993, vol. 33, pp. 529-38.

22. C. Wu and V. Sahajwalla: Metall. Mater. Trans. B, 2000, vol. 31B, pp. $243-51$.
23. R. Olivares: Ph.D. Dissertation, University of Newcastle, Newcastle, Australia, 1996.

24. R.H. Davies, A.T. Dinsdale, J.A. Gisby, S.M. Hodson, and R.C.J. Ball: Conf. on Applications Thermodynamics on the Synthesis and Processing of Materials, ASM/TMS, Rosemont, IL, 1994, pp. 37184.

25. E.T. Turkdogan: Fundamentals of Steelmaking, The Institute of Materials, Cambridge, U.K., 1996, pp. 10-95.

26. J.F. Elliott, M. Gleiser, and V. Ramakrishna: Thermochemistry for Steelmaking, vol. 2, Addison-Wesley, Cambridge, U.K., 1963, pp. 709-16. 